\title{
Reason and Rationality in Paul C Mocombe's Theory of Phenomenological Structuralism
}

\section{Mocombe PC*}

West Virginia State University, USA

*Corresponding author: Paul C Mocombe, West Virginia State University, The Mocombeian Foundation, Inc., USA, Email: pmocombe@mocombeian.com

\section{Research article}

Volume 3 Issue 2

Received Date: April 10, 2020

Published Date: May 12, 2020

DOI: $10.23880 /$ phij-16000143

\section{Abstract}

This work explores the nature of reason and rationality in Paul C. Mocombe's structurationist theory of phenomenological structuralism. The author, building on the quantum computation of ORCH-OR theory and the multiverse ideas of Haitian ontology/epistemology and quantum mechanics abductively posits that consciousness is a fifth force of nature, a quantum material substance/energy, psychion, the phenomenal property of which is recycled/entangled/superimposed throughout the multiverse and becomes embodied via the microtubules of brains and multiple worlds. It is manifested in simultaneous, entangled, superimposed, and interconnecting material resource frameworks, multiple worlds, as praxis or practical consciousness of organic life, which in-turn becomes the phenomenal properties of material (subatomic particle energy, psychion) consciousness that is recycled/entangled/superimposed throughout the multiverses. Reason and rationality within this conception of consciousness are posited as both the form of the understanding by which the human organism experiences and makes sense of their material resource frameworks, and the nature of reality as such.

Keyword: Structurationism; Praxis; Panpsychism; Social Class Language Game; Phenomenological Structuralism; ORCH-OR Theory

\section{Introduction}

This work explores the nature of reason and rationality in Paul C Mocombe's structurationist theory of phenomenological structuralism. The author, building on the quantum computation of ORCH-OR theory and the multiverse ideas of Haitian ontology/epistemology and quantum mechanics abductively posits that consciousness is a fifth force of nature, a quantum material substance/ energy, psychion, the phenomenal property, qualia, of which is recycled/entangled/superimposed throughout the multiverse and becomes embodied via the microtubules of brains and multiple worlds. It is manifested in simultaneous, entangled, superimposed, and interconnecting material resource frameworks, multiple worlds, as praxis or practical consciousness of organic life, which in-turn becomes the phenomenal properties, qualia, of material (subatomic particle energy, psychion) consciousness that is recycled/ entangled/superimposed throughoutthe multiverses. Reason and rationality within this conception of consciousness are posited as both the form of the understanding by which the human organism experiences and makes sense of their material resource frameworks, and the mechanisms by which we can grasp the nature of reality as such. The former is done through the purposive-rationality of the ordinary language, ideology, ideological apparatuses, communicative discourse, and mode of production of the power elites of a dominant social class language game of a material resource framework, and the latter via the language of science and religion, which attempts to capture the nature and structure of reality as such, which is deemed to be rational in the Hegelian sense $[1,2]$. 


\section{Philosophy International Journal}

\section{Background of the Problem}

Reason and rationality in Western philosophy have been viewed as that which both sets human beings apart from other species and the constitutive basis of the nature of reality as such, on the one hand; and on the other hand, they are downplayed as the slaves of the passions. In either positions, to accept something as reasonable or rational, "is to accept it as making sense, as appropriate, or required, or in accordance with some acknowledged goal, such as aiming at truth or aiming at the good". In Paul C. Mocombe's (2019) theory of phenomenological structuralism, reason and rationality are viewed as the constitutive basis of the multiverse, which the human mind can grasp in order to structure their reality through the language of science/ religion amidst the emotionality of ordinary language and its actions. So for Mocombe, building on the epistemology of Bertrand Russell, two distinct language systems characterize human consciousness and societies: ordinary language and its praxis or speech acts (language games), which is tied to the passions and unconscious drives of the species as they experience being-in-a-material-resource framework; and the language of science/religion, which attempts to capture the "True" ontological and epistemological basis of the nature of reality as such as rationally constituted by the forces of the multiverse. The two are rooted in the consciousness of the human species, which is tied to nature, are mutually exclusive, and diametrically oppose one another.

\section{Theory and Methods}

Consciousness here refers to subjective awareness of phenomenal experiences (ideology, language, self, feelings, choice, control of voluntary behavior, thoughts, etc.) of internal and external worlds. The academic literature "describes three possibilities regarding the origin and place of consciousness in the universe: (A) as an emergent property of complex brain neuronal computation, (B) as spiritual quality of the universe, distinct from purely physical actions, and (C) as composed of discrete 'proto-conscious' events acting in accordance with physical laws not yet fully understood" [3]. The latter position, (C), represents the ORCH-OR ("orchestrated objective reduction") theory of Stuart Hameroff and Roger Penrose, which includes aspects of (A) and (B), and posits that "consciousness consists of discrete moments, each an 'orchestrated' quantumcomputational process terminated by... an action [,objective reduction or $\mathrm{OR}$,] rooted in quantum aspects of the fine structure of space-time geometry, this being coupled to brain neuronal processes via microtubules" (pg. 70). In this view, the understanding is that a proto-conscious experience existed in the universe, panpsychism, and as a result of emergent structures of the brain it (proto-conscious experience, psychion) became embodied and evolved as a result of quantum neuronal computations of "brains."

Paul C. Mocombe's [1,2] structurationist sociology, phenomenological structuralism, which attempts to resolve the structure/agency problematic of the social sciences, builds on the ORCH-OR theory and panpsychism of Hameroff and Penrose, while holding on to the multiverse hypothesis of quantum mechanics and Haitian ontology/ epistemology, which the authors reject because it is not "a more down-to-earth viewpoint" [3]. For Mocombe [1,2], quantum superposition, entanglement, wave-function realism, and evidence in Haitian Vodou of spirit possession, which represent ancestors from a parallel world, Vilokan, of the earth's of which we ought to pattern our behaviors and structures, are grounding proofs for the acceptance of the multiple worlds hypothesis of quantum mechanics. Within the latter hypothesis, the understanding is that "each possibility in a superposition evolves to form its own universe, resulting in an infinite multitude of coexisting 'parallel' worlds. The stream of consciousness of the observer is supposed somehow to 'split', so that there is one in each of the worlds-at least in those worlds for which the observer remains alive and conscious. Each instance of the observer's consciousness experiences a separate independent world, and is not directly aware of any of the other worlds" [3]. It is within this multiple worlds hypothesis that Mocombe constitutes the notion of consciousness in the universe according to his theory of phenomenological structuralism. For Mocombe, consciousness is a fifth force of nature, a quantum material substance/energy, psychion, the phenomenal property, qualia, of which is recycled/entangled/ superimposed throughout the multiverse and becomes embodied via the microtubules of brains. It (consciousness) is manifested in simultaneous, entangled, superimposed, and interconnecting material resource frameworks as embodied praxis or practical consciousness, which in-turn becomes the phenomenal properties, qualia, of material (subatomic particle energy, psychion) consciousness that is recycled/ entangled/superimposed throughout the multiverses.

\section{Theory and Method}

Structurationist sociology synthesizes structure and agency via the concept of praxis or practical consciousness; accounting for human agency or practical consciousness via the actions associated with structural reproduction and differentiation within a particular material resource framework [4,5]. This latter factor, however, does not account for the moments or movements, which escape from the compound of socially constructed identifications. Building on structurationist sociology, Mocombe argues that the "moments, or movements, which escape from the compound of socially constructed identifications" are the product of an individual actors' (mental) stance/analytics (Martin 


\section{Philosophy International Journal}

Heidegger's term) vis-à-vis three types of structures/systems of signification amidst the practical consciousness associated with societal structural reproduction and differentiation (the social system):

1) The (chemical, biological, and physiological) drives (forms of sensibility and understanding) of the body and brain (the biological system).

2) Impulses or phenomenal properties of residual past/ present/future consciousnesses or recycled/entangled/ superimposed subatomic/chemical particles encapsulated in and as the neuronal energies of the brain via microtubules (the physical system).

3) Actions or practical consciousnesses resulting from the deferment of meaning in ego-centered linguistic and symbolic communicative discourse (the linguistic system).

Generally speaking, consciousnesses, actions (practical consciousness), learning, and development within Mocombe's phenomenological structural ontology are the product of the embodiment of the phenomenal properties, qualia, of recycled/entangled/superimposed subatomic neuronal energies/chemicals, psychion, of the multiverse objectified in the space-time of multiverses via the aggregated body and the microtubules of the brain. Once objectified and embodied the phenomenal properties of the neuronal energies/chemicals encounter the space-time of physical worlds via a transcendental subject of consciousnesses (the aggregation of a universal-self superimposed and entangled across the multiple worlds of the multiverse) and the drives and sensibilities of the aggregated body and brain in reified structures of signification, language, ideology, ideological apparatuses, and communicative discourse defined and determined by other beings that control the resources (economics), and modes of distributing them, of the material world required for physical survival in space-time. The Heideggerian (mental) stances/analytics, "ready-to-hand," "unready-to-hand," and "present-at-hand," which emerge as a result of conflict between the embodied transcendental ego vis-à-vis its different systems

1) The sensibilities and (chemical, biological, and physiological) drives of the body and brain.

2) Drives/impulses of embodied residual memories or phenomenal properties of past/present/future recycled/ entangled/superimposed subatomic/chemical particles.

3) The actions produced via the body in relation to the indeterminacy/deferment of meaning of linguistic and symbolic signifiers as they appear to individuated consciousnesses in ego-centered communicative discourse.

4) The dialectical and differentiating effects, i.e., structural reproduction and differentiation, of the structures of signification, social class language game, of those who control the economic materials (and their distribution, i.e., mode of production) of a world are the origins of practical consciousnesses. All four types of actions, the drives and sensibilities of the body and brain, drives or phenomenal properties of embodied recycled/entangled/superimposed past consciousnesses, structural reproduction/ differentiation stemming from the mode of production, and deferential actions arising from the deferment of meaning in ego-centered communicative discourse via the presentat-hand stance/analytic, exist in the material world with the social class language game, i.e., the physical, mental, emotional, ideological, etc.

5) Powers of those who control the material resource framework as the causative agent for individual behaviors. In other words, our (mental) stances in consciousness visà-vis the conflict between the (chemical, biological, and physiological) drives and sensibilities of the body and brain, (societal) structural reproduction and differentiation, drives of embodied past/present/future consciousnesses of recycled/entangled/superimposed subatomic/chemical particles, and deferential actions arising as a result of the deferment of meaning in ego-centered communicative discourse determines the practical consciousness we want to recursively reorganize and reproduce in the material world. The power and power positions of those who control (via the mode of production, language, ideology, ideological apparatuses, and communicative discourse) the resources (and their distribution, i.e., mode of production) of a material resource framework, and the threat it poses to the ontological security of an actor, in the end determines what actions and identities are allowed to organize and reproduce in the material world without the individual actor/agent facing marginalization or death.

It is Being's (mental) stance/analytic, "ready-to-hand," "unready-to-hand," and "present-at-hand," in consciousness vis-à-vis the conflict, or lack thereof, between the (chemical, biological, and physiological) drives and sensibilities of the aggregated body and brain, drives/impulses (phenomenal properties) of residual past/present/future consciousnesses of recycled/entangled/superimposed subatomic particles, alternative practices which arise as a result of phenomenological meditation and deferment of meaning, along with the differentiating logic or class divisions of the social relations of production, which produces the variability of actions and practices in cultures, social structures, or social systems. All four types of actions are always present and manifested in a social structure to some degree contingent upon the will and desires of the economic social class, power elites, which controls the material resource framework through its body (practical consciousness), language/symbols, ideology, ideological apparatuses, and social relations of production. They choose, amidst the class division of the social relations of production, what other meaning constitutions and practices are allowed to manifest themselves in the material world without facing alienation, marginalization, domination, or death. 


\section{Philosophy International Journal}

Hence, we never experience the things-in-themselves of the world culturally and historically in consciousness. We experience them structurally or relationally, the structure of the conjuncture of the mode of production, its language, ideology, ideological apparatuses, etc., and our (mental) stances/analytics, ready-to-hand, unready-to-hand, presentat-hand, vis-à-vis these things as they appear to and in consciousness determine our practical consciousness or behaviors.

We initially know, experience, and utilize the things of and in consciousness in the preontological ready-tohand mode, which is structural and relational. That is, our bodies encounter, know, experience, and utilize the things of the world in consciousness, intersubjectively, via their representation as objects of knowledge, truth, usage, and experience enframed and defined in the relational logic and practices or language game (Wittgenstein's term) of the institutions or ideological apparatuses of the other beingsof-the-material resource framework whose historicity comes before our own and gets reified in and as the actions of their bodies, language, ideology, ideological apparatuses, mode of production, and communicative discourse. This is the predefined phenomenal structural, i.e., ontological, world we and our bodies are thrown-in in coming to be-inthe-world. How an embodied-hermeneutically-structured Being as such solipsistically view, experience, understand, act, and utilize the predefined objects of knowledge, truth, and experienced defined by others and their conditions of possibilities in consciousness in order to formulate their practical consciousness is albeit indeterminate. Martin Heidegger in Being in Time is accurate, however, in suggesting that three stances or modes of encounter (Analytic of Dasein), "presence-at-hand," "readiness-tohand," and "un-readiness-to-hand," characterizes our views of the things of consciousness represented intersubjectively via bodies, language, ideology, and communicative discourse, and subsequently determine our practical consciousness or social agency. In "ready-to-hand," which is the preontological mode of human existence thrown in the world, we accept and use the things in consciousness with no conscious experience of them, i.e., without thinking about them or giving them any meaning or signification outside of their intended usage. Heidegger's example is that of using a hammer in hammering. We use a hammer without thinking about it or giving it any other condition of possibility outside of its intended usage as defined by those whose historicity presupposes our own. In "present-at-hand," which, according to Heidegger, is the stance of science, we objectify the things of consciousness and attempt to determine and reify their meanings, usage, and conditions of possibilities as the nature of reality as such. Hence the hammer is intended for hammering by those who created it as a thing solely meant as such. The "unready-tohand" outlook is assumed when something goes wrong in our usage of a thing of consciousness as defined and determined by those who adopt a "present-at-hand" view. As in the case of the hammer, the unready-to-hand view is assumed when the hammer breaks and we must objectify it, by then assuming a present-at-hand position, and think about it in order to either reconstitute it as a hammer, or give it another condition of possibility. Any other condition of possibility that we give the hammer outside of its initial condition of possibility which presupposed our historicity becomes relational, defined in relation to any of its other conditions of possibilities it may have been given by others we exist in the world with who either ready-to-hand, unready-to-hand, or present-at-hand attempts to maintain the social class language game of power. In the ready-to-hand stance the latter unconsciously practices and attempts to reproduce the social class language game of power by discriminating against and marginalizing any other conditions of possibilities of their social class language as determined by those in ideological power positions. They may move to the unready-to-hand stance in response to those who they encounter that attempts, present-at-hand, to alter the nature of the dominant social class language game they recursively reorganize and reproduce as outlined by those in power positions who are present-at-hand of the dominant social class language game. In either case, not all beings achieve the present-at-hand stance. The latter is the stance of science and ideologies, which are tautologies when they profess that their stances represent the nature of reality as such, and those in power positions, who choose, among a plethora of alternative present-at-hand social class language games, what alternative practical consciousnesses outside of their social class language game that are allowed to manifest in the material world.

\section{Discussion}

Hence, as outlined above, phenomenological structuralism posits consciousness to be the by-product or evolution of subatomic particles, psychion, with phenomenal properties, qualia, unfolding with increasing levels of abstraction within a material resource framework enframed by the mode of production, language, ideology, ideological apparatuses, and communicative discourse of bodies recursively reorganizing and reproducing the ideals of the latter factors as their practical consciousness. That is to say, the logical consequence regarding the evolution and constitution of the multiverses, and their contents, based on the assumptions of superposition, action-at-adistance, wave-function realism, phenomenal properties, and panpsychism of quantum mechanics, for Mocombe, is similar to the intersecting worlds theory highlighted in Haitian Vodou, which parallels the physics, "membrane theory," of Lisa Randall and Raman Sundrum (1999). The proposal in keeping with the logic of Haitian Vodou and the "brane theory" of Randall and Sundrum is that there might 


\section{Philosophy International Journal}

be an additional dimension on the cosmological scale, the scale described by general relativity, which gives rise to four dimensional multiverses within it. That is to say, our universe is embedded in a vastly bigger five-dimensional space (the four-dimensional space of relativity, plus a fifth dimension for the subatomic forces including consciousness), a kind of super-universe. Within this super-space, our universe is just one of a whole array of co-existing universes (Haitian Vodou only accounts for our universe and its parallel), each a separate four-dimensional bubble within a wider arena of five-dimensional space where consciousness (a subatomic force) is recycled/entangled/superimposed between the five-dimensional super-space, i.e., superverses, and their multiverses.

For Mocombe the multiverses originated, from the super-universes, either by fiat or quantum fluctuation. They are bosonic forces that were brought forth together with fermion counterparts. They are also the primeval pan-psychic fields, stemming from the super-verses, whose fermion can be called a psychion, a particle of consciousness or proto-consciousness. These have evolved together to produce the four forces of nature, electromagnetic force; gravity; the strong nuclear force; and weak nuclear force, in our universe, which in turn produced atoms, molecules, and aggregated life endowed (embodied) with the recycled/ entangled/superimposed consciousness and phenomenal properties of the primeval pan-psychic fields, psychion, of the superverses and their multiverses (the fifth force of nature). Subatomic particles, via the Higgs boson particle, gave rise to carbon atoms, molecules and chemistry, which gave rise to DNA, biological organisms, neurons and nervous systems, which aggregated into bodies and brains that gave rise to the embodiment of preexisting consciousness of the subatomic particles, bodies, and languages from entangled/superimposed multiverses. In human beings, the indeterminate behavior of superimposed and entangled subatomic neuronal energies that produced the plethora of consciousnesses and languages in the neocortex of brains gave rise to ideologies, which in turn gave rise to ideological apparatuses and societies (sociology) under the social class language game or language, ideology, and ideological apparatuses of those who organize and control the material resources (and their distribution) required for physical (embodied) survival in a particular resource framework. So contrary to Karl Marx's [6-8] materialism which posits human consciousness to be the product of material conditions, the logic here is a structural Marxist one in the Althusserian sense $[9,10]$. That is, the aggregated, atomic, mature human being is a body and neuronal drives that never encounters the (ontological) material world directly. Instead, they encounter the (ideological) world via structures of signification, which structures the world or a particular part of it through the body, language, ideology, ideological apparatuses, and communicative discourse, i.e., social class language game, of those whose power and power positions dictate how the resources of that framework are to be gathered, used, and distributed (means and mode of production).

Hence in the end, subject constitution is a product of conflict and an individual's mental stance, i.e., analytics, vis-à-vis three structures/systems of signification and the ability to defer meaning in ego-centered communicative discourse stemming from the social class language game (i.e., language, symbols, ideology, ideological apparatuses, and communicative discourse) of those who control the mode of production of a material resource framework. It is the ready-to-hand drives of the body and brain, ready-to-hand and present-at-hand manifestation of past/present/future recycled residual consciousnesses/subatomic particles, the present-at-hand phenomenological meditation and deferment of meaning that occurs in embodied consciousness via language, ideology, and communicative discourse as reflected in diverse individual practices, within the ready-tohand, unready-to-hand, and present-at-hand differentiating logic or class divisions of the social relations of production, which produces the variability of actions and practices in cultures, social structures, or social systems. All four types of actions, the (chemical, biological, and physiological) drives/ impulses of the body and residual past consciousnesses of subatomic particles, structural reproduction/differentiation, and actions resulting from the deferment of meaning in egocentered communicative discourse, are always present and manifested in a social structure (which is the reified ideology via ideological apparatuses, their social class language game, of those who control a material resource framework) to some degree contingent upon the will and desires of the economic social class that controls the material resource framework through the actions of their bodies (practical consciousness), language, symbols, ideology, ideological apparatuses, and social relations of production. They choose, amidst the class division of the social relations of production, "the structure of the conjuncture," (Marshall Sahlins's term) what other meaning constitutions and practices are allowed to manifest themselves without the Beings of that practice facing alienation, marginalization, domination, or death [1120].

The individual being is initially constituted as superimposed, entangled, recycled, and embodied subatomic particles of multiple worlds of the multiverse, which have their own predetermined form of understanding and cognition, phenomenal properties, qualia, based on previous or simultaneous experiences as aggregated matter (this is akin to what the Greek philosopher Plato refers to when he posits knowledge as recollection of the Soul). Again, the individual's actions are not necessarily determined by the embodiment 


\section{Philosophy International Journal}

and drives of these recycled/entangled/superimposed subatomic particles. It is conflict and an individual's stance, ready-to-hand, unready-to-hand, and present-at-hand, when the subatomic particles become aggregated matter or embodied, which determines whether are not they become aware, present-at-hand, of the subatomic particle drives and choose to recursively reorganize and reproduce the content of the drives as their practical consciousness [21-25].

This desire to reproduce the cognition and understanding of the (chemical, biological, and physiological) drives of the recycled/entangled/susperimposed subatomic particles, however, may be limited by the structuring structure of the aggregated body and brain of the individual subject. That is to say, the second origins and basis of an individual's actions are the structuring drives and desires, for food, clothing, shelter, social interaction, and sex, of the aggregated body and brain, which the subatomic particles constitute and embody. In other words, the aggregated body and brain is preprogrammed with its own (biological) forms of sensibility, understanding, and cognition, structuring structure, by which it experiences being-in-the-world as aggregated embodied subatomic particles. These bodily forms of sensibility, understanding, and cognition, such as the drive and desire for food, clothing, shelter, social interaction, linguistic communication, and sex, are tied to the material embodiment and survival of the embodied individual actor, and may or may not supersede or conflict with the desire and drive of an individual to recursively (re) organize and reproduce the structuring structure of the superimposed, entangled, and recycled (phenomenal properties of) subatomic particles. If these two initial structuring structures are in conflict, the individual moves from the ready-to-hand to the unreadyto-hand stance or analytics where they may begin to reflect upon and question their being-in-the-world prior to acting. Hence just as in the case of the structuring structure of the subatomic particles it is an individual being's analytics vis-àvis the drives of its body and brain in relation to the impulses of the subatomic particles, which determines whether or not they become driven by the desire to solely fulfill the material needs of their body and brain at the expense of the drives/desires of the subatomic particles or the social class language game of the material resource framework they find their existence unfolding in.

The social class language game, and its differentiating effects, an individual find their existence unfolding in is the third structuring structure, which attempts to determine the actions of individual beings as they experience being-inthe-world as embodied subatomic particles. The aggregated individual finds themselves objectified and unfolding within a material resource framework controlled by the actions of other bodies, which presuppose their existence, via the actions of their bodies (practical consciousness), language, communicative discourse, ideology, and ideological apparatuses stemming from how they satisfy the desires of their bodies and subatomic particle drives (means and mode of production). What is aggregated as a social class language game by those in power positions via and within its mode of production, language, ideology, ideological apparatuses, and communicative discourse attempts to interpellate and subjectify other beings to its interpretive frame of satisfying their bodily needs, fulfilling the impulses of their subatomic particles, and organizing a material resource framework at the expense of all others, and becomes a third form of structuring individual action based on the mode of production and how it differentiates individual actors.

That is to say, an individual's interpellation, subjectification, and differentiation within the social class language game that presupposes their being-in-aworld attempts to determine their actions or practical consciousness via the reified language, ideology, etc., of the social class language game, the meaning of which can be deferred via the communicative discourse of the individual actors allowing them to form social groups or heterogeneous communities tied to the dominant social order because of their control of the materials of the material resource framework.. Hence, the deferment of meaning in ego-centered communicative discourse of the language and ideology of a social class language game is the final means of determining an individual's action or practical consciousness outside of, and in relation to, its stance, i.e., analytics, vis-à-vis the drives of subatomic particles, drives and desires of the body and brain, and structural reproduction and differentiation.

Whereas the practical consciousness of the transcendental ego stemming from the impulses of embodied subatomic particles are indeterminant as with its neuronal processes involved with the constitution of meaning in egocentered communicative discourse (Albeit physicists are in the process of exploring the nature, origins, and final states of subatomic particles, and neuroscientists are attempting to understand the role of neuronal activities in developing the transcendental ego and whether or not it continues to exist after death). The form of the understandings and sensibilities of the body and brain are determinant as with structural reproduction and differentiation of the mode of production, and therefore can be mapped out by neuroscientists, biologists, and sociologists to determine the nature, origins, and directions of societal constitution and an individual actor's practical consciousness unfolding.

The interaction of all four elements or processes in relation to the (mental) stance of the transcendental ego of the individual actor is the basis for human action, praxis/ practical consciousness, and cognition in a world. However, in the end, consequently, the majority of practical consciousness 


\section{Philosophy International Journal}

will be a product of an individual actor's embodiment and the structural reproduction and differentiation of a social class language game given 1) the determinant nature of embodiment, form of understanding and sensibility of the body and brain amidst, paradoxically, the indeterminacy of impulses of embodied subatomic particles and the neuronal processes involved in ego-centered communicative discourse; and 2) the consolidation of power of those who control the material resource framework wherein a society, the social class language game, is ensconced and the threat that power (consolidated and constituted via the actions of bodies, mode of production, language, ideology, ideological apparatuses, and communicative discourse) poses to the ontological security of an aggregated individual actor who chooses (or not) either ready-to-hand or present-athand to recursively reorganize and reproduce the ideals of the society as their practical consciousness. It should be mentioned that in response to this latter process, those in power positions who internalize the ideals of the social structure and recursively (re) organize and reproduce them as their practical consciousness are in the unready-to-hand stance when they encounter alternative forms of beingin-the-world within their social class language game. They dialectically attempt to reconcile the practical consciousness of their social class language game with the reified practical consciousness of those who have deferred their meanings for alternative forms of being-in-the-world within their social class language. They can either accept, marginalize, or seek to eradicate the deferred or decentered subject or their practices [25-37].

\section{Conclusions}

Hence within the theory and methodology of phenomenological structuralism two rational linguistic systems emerged and emerges in human affairs, ordinary language, which captures the daily activities, purposiverationality, of the dominant social class language game and its different heterogeneous communities; and the language of science and religion, which utilizes reason and rationality to attempt to capture the nature of reality as such by which human activities ought to be reproduced in the material resource framework. Thus, there is, contrary to David Hume's "bundle of perception" hypothesis, a human essence, which is tied to the embodiment and structuring structure of the phenomenal properties, qualia, of superimposed, entangled, embodied, and recycled subatomic particles, the processes of which are unbeknownst to us as of the writing of this work, as they are recursively reorganized and reproduced via the superverse and its multiverses. Just the same, Universalism and Truth are also tied to the science and physics of the remaining processes of phenomenological structuralism. Subatomic/chemical particles with phenomenal properties constitute objects and subjects that are external and internal to the perceiving human actor who know them (the objects and subjects) as both external and internal phenomenon endowed with, and mediated by, linguistic and ideological meanings, stemming from the modes of production, of other human actors who presupposed their aggregated existence. The essence, universalism, and Truth of an object and subject lies in the phenomenal properties of their subatomic and chemical particles once demystified and demythologized, from linguistic and ideological meanings and understandings associated with the mode of human production, by the techniques of phenomenology and the scientific process. Be that as it may, for phenomenological structuralism, in keeping with the empiricist logic of Bertrand Russell, "outside of human desires there are no moral standards." Morality or moral standards are associated with the linguistic and ideological desires (power and power positions) of those who control the resources and mode of production of a material resource framework via their language, ideology, ideological apparatuses, and communicative discourse (i.e., social class language game). It (moral practices and statements) constitutes a part of the superverse/multiverse as phenomenal properties of subatomic particles once disaggregated as lived-experience. In that sense, assuming the phenomenal properties of subatomic particles get recycled between the superverse and its multiverses as I am positing here, morality is an epiphenomenon of lived-experience and becomes an emergent property of the superverse and its multiverses, which constitute the lwas (platonic forms or concepts such as beauty, justice, egalitarianism, etc.) of Haitian metaphysics that human reason, which are the recycled/entangled/superimposed subatomic neuronal/chemical particles of the superverse and multiverse operating through DNA and its aggregation as the brain and mind (perception), can reflect upon to constitute their being-in-the-world (practical consciousness) in relation to the language, ideology, etc., i.e., social class language game and its heterogenous communities, of those who precedes individual existence. Ostensibly, social change, following subatomic particle aggregation, is tied to both the 1) differentiating effects and techniques of the social class language game of those who control the material resource framework of (an) earth, 2) and the ability to defer meaning in ego-centered communicative discourse, via symbols, language, ideology, etc., which encapsulates or is the medium by which the lwas (concepts) of the superverse and its multiverses are expressed as human practical consciousness in material worlds. The latter takes place within the background of the language, reason, and practical-rationality of science/religion, which attempts to capture the nature of reality as such.

\section{References}

1. Mocombe PC (2016) The Vodou Ethic and the Spirit of 


\section{Philosophy International Journal}

Communism: The Practical Consciousness of the African People of Haiti. Maryland: University Press of America.

2. Mocombe PC (2009) The Soul-less Souls of Black Folk: A Sociological Reconsideration of Black Consciousness as Du Boisian Double Consciousness. Maryland: University Press of America.

3. Hameroff S, Roger $P$ (2014) Consciousness in the Universe: A Review of the 'Orch OR' theory. Physics of Life Reviews 11: 39-78.

4. Crothers C (2003) Technical Advances in General Sociological Theory: The Potential Contribution of PostStructurationist Sociology. Perspectives, 26: 3, 3-6.

5. Ortner S (1984) Theory in Anthropology Since the Sixties, Comparative Studies in Society and History 26: 126-66.

6. Marx K, Friedrich E (1964) The Communist Manifesto. London, England: Penguin Books.

7. Marx K (1992 [1867]) Capital: A Critique of Political Economy. $1^{\text {st }}$ (Vol.), Samuel M, Edward A (Trans.). New York: International Publishers.

8. Marx K (1998 [1845]) The German Ideology. New York: Prometheus Books.

9. Althusser L (2001) Lenin and Philosophy and Other Essays. New York: Monthly Review Press.

10. Althusser L, Étienne B (1970) Reading Capital (Ben Brewster, Trans.). London: NLB.

11. Balibar E, Immanuel W (1991 [1988]) Race, Nation, Class: Ambiguous Identities. London: Verso.

12. Buck-Morss S (2009) Hegel, Haiti, and Universal History. Pittsburgh: University of Pittsburgh Press.

13. Cohen J (2002) Protestantism and Capitalism: The Mechanisms of Influence. New York: Aldine de Gruyter.

14. Dahrendorf R (1959) Class and Class Conflict in Industrial Society. Stanford, California: Stanford University Press.

15. Douglas M (1986) How Institutions Think. New York: Syracuse University Press.

16. Du Bois L (2004) Avengers of the New World. Massachusetts: Harvard University Press.

17. Fraser N (1997) Justice Interruptus: Critical Reflections on the "Postsocialist" Condition. New York \& London: Routledge.
18. Holloway JE (1990a) Africanisms in American Culture. Bloomington and Indianapolis: Indiana University Press.

19. Holloway JE (1990b) The Origins of African-American Culture. In: Joseph H (Ed.), Africanisms in American Culture. Bloomington and Indianapolis: Indiana University Press, pp: 19-33.

20. Horkheimer M, Theodor WA (2000 [1944]) Dialectic of Enlightenment (John Cumming, Trans.). New York: Continuum.

21. Hudson K, Andrea C (2005) The Dark Side of the Protestant Ethic: A Comparative Analysis of Welfare Reform. Sociological Theory 23 (1): 1-24.

22. James CLR (1986) The Black Jacobins: Toussaint L' Ouverture and the San Domingo Revolution. Vintage

23. Karenga M (1993) Introduction to Black Studies. California: The University of Sankore Press.

24. Kellner D (2002) Theorizing Globalization. Sociological Theory, 20: 3,285-305.

25. Kurtz LR (2007) Gods in the Global Village: The World's Religions in Sociological Perspective. California: Sage Publications.

26. Lukács G (1971) History and Class Consciousness: Studies in Marxist Dialectics (Rodney Livingstone, Trans.). Cambridge, Massachusetts: The MIT Press.

27. Lukács G (2000) A Defence of History and Class Consciousness: Tailism and the Dialectic (Esther Leslie, Trans.). London and New York: Verso.

28. Marcuse H (1964) One-Dimensional Man. Boston: Beacon Press.

29. Marcuse H (1974) Eros and Civilization: A Philosophical Inquiry into Freud. Boston: Beacon Press.

30. McMichael P (2008) Development and Social Change: A Global Perspective. Los Angeles, California: Sage Publications.

31. Patterson O (1982) Slavery and Social Death: A Comparative Study. Cambridge, Massachusetts: Harvard University Press.

32. Ramsey K (2011) The Spirits and the Law: Vodou and Power in Haiti. Chicago: University of Chicago Press.

33. Rubin V (1960) Caribbean Studies: A Symposium. Seattle: University of Washington Press.

34. Sklair L (1995) Sociology of the Global System. Baltimore: 
Westview Press.

35. Smith MG (1960) The African Heritage in the Caribbean. In: Vera R (Ed.), Caribbean Studies: A Symposium. Seattle: University of Washington Press, pp: 34-46

36. Wallerstein I (1982) The Rise and Future Demise of the World Capitalist System: Concepts for Comparative
Analysis. In: Hamza A, Teodor S (Eds.), Introduction to the Sociology of "Developing Societies". New York: Monthly Review Press, pp: 29-53.

37. Weber M (1958 [1904-1905]) The Protestant Ethic and the Spirit of Capitalism (Talcott Parsons, Trans.). New York: Charles Scribner's Sons. 